\title{
Spectral UV measurements over Europe within the Second European Stratospheric Arctic and Midlatitude Experiment activities
}

\author{
A. F. Bais, ${ }^{1}$ M. Blumthaler, ${ }^{2}$ A. R. Webb, ${ }^{3}$ J. Groebner, ${ }^{4}$ P. J. Kirsch, ${ }^{5}$ \\ B. G. Gardiner, ${ }^{5}$ C. S. Zerefos, ${ }^{1}$ T. Svenoe, ${ }^{6}$ and T. J. Martin ${ }^{5}$
}

\begin{abstract}
In the frame of the Second European Stratospheric Arctic and Midlatitude Experiment an intensive program of spectral measurements of global solar UV radiation was organized at several European sites, extending from middle latitudes to the Arctic Circle, in March 1995. Before starting the intensive measurements, a 2-day intercomparison was performed at each site with a traveling spectrophotometer to ensure consistency and comparability between the instruments and their measurements during the period of the study. The collected data were used to investigate the variability of solar ultraviolet irradiances at high and middle latitudes during a period of considerably varying ozone levels. The ratio of the UV erythemal irradiance to UVA irradiance was used to exclude the interference of clouds and other wavelength independent factors. Finally, a simple statistical analysis of the data showed that the variability of UV erythemal dose due to clouds can be at least of similar importance to that induced by the variability of total ozone.
\end{abstract}

\section{Introduction}

Within the Second European Stratospheric Arctic and Midlatitude Experiment (SESAME) a wide variety of measurements was performed at several locations in the Arctic region and at selected sites at middle latitudes of the northern hemisphere. Among the main objectives of SESAME was the collection of high-quality measurements of various atmospheric species, which would help in better understanding the stratospheric chemistry of chlorine, nitrogen, and bromine compounds, as well as the role of polar stratospheric clouds and meteorology in the ozone variability in these regions. Since the variability of the ozone layer is the major controlling factor of the solar ultraviolet radiation transfer through the Earth's atmosphere, studies related to solar UV radiation were also included in SESAME objectives. Despite their importance, detailed spectral measurements of solar UV irradiances are currently available only at a limited number of sites in the Arctic region [Bais et al., 1994; Svenoe et al., 1994; Jokela et al., 1993; Henriksen et al., 1992].

Therefore an intensive program of spectral UV measurements was set up at selected sites in the European part of the northern hemisphere by a group of institutes operating well-maintained ultraviolet spectroradiometers. The aim of these measurements was to obtain a detailed data set which would help in understanding the physics and the spatial and temporal variability of

\footnotetext{
'Laboratory of Atmospheric Physics, Aristotle University of Thessaloniki, Thessaloniki, Greece.

${ }^{2}$ Institute of Medical Physics, University of Innsbruck, Innsbruck, Austria.

${ }^{3}$ Institute of Science and Technology, University of Manchester, England.

${ }^{4}$ Atmospheric Environment Service, Environment Canada, North York, Ontario, Canada.

${ }^{5}$ British Antarctic Survey, Cambridge, England.

Gorwegian Institute for Air Research, Tromsoe, Norway.

Copyright 1997 by the American Geophysical Union.

Paper number 96JD03584.

$0148-0227 / 97 / 96 \mathrm{JD}-03584 \$ 09.00$
}

solar ultraviolet radiation reaching the ground. Moreover, the existence of such a data set, in conjunction with other UVrelated information produced by a variety of SESAME experiments, would be invaluable for testing and validation of radiative transfer models. Vertical profiles of ozone and aerosols, as well as in situ measurements of various UV-absorbing chemical compounds, are among those measurements that were included in the SESAME campaign and that can be used in modeling studies. In addition, the geographical location of the measurements (Arctic region) during a season (spring) with strong atmospheric variability and chemical activity makes this data set even more important. To the knowledge of the authors, this is the first time that coordinated, intensive solar UV spectral measurements, covering a wide range of latitudes, have been performed over northem Europe.

The scope of this work is to use the measurements obtained during this intensive campaign to study the variability of solar UV irradiance received at the ground, induced by variations of the ozone layer. In addition, the ozone-induced variability will be compared with that caused by clouds and by the latitudinal differences between the sites. From the technical point of view, one important aspect of this campaign was also to test the performance and stability of very sensitive and delicate instruments, such as UV spectroradiometers, when moved to remote locations far from their regular operating sites. Finally, it should be mentioned that testing and validation of radiative transfer models with the use of this data set will be carried out and reported separately.

\section{Instrumentation and Data}

Several types of instruments were used in this campaign. These are listed in Table 1, together with their main technical characteristics. All instruments were capable of recording the global solar UV irradiance, at least in the UVB spectral region, in steps of $0.5 \mathrm{~nm}$, and they were all using cosine diffusers as input optics. The absolute calibration of the instruments was maintained by using working standards of spectral irradiance, except for the Brewer instrument at Thessaloniki, Greece, which 
Table 1. Sites and Instrumentation Used for This Study

\begin{tabular}{lcccccc}
\hline Location & Latitude, ${ }^{\circ} \mathrm{N}$ & Code & Instrument Type & Spectrometer & Slit FWHM, nm & Spectral Range, nm \\
\hline Esrange, Sweden & 67.9 & ATI & Bentham DM150 & double & 0.76 & $280-500$ \\
Reykjavik, Iceland & 64.1 & GRR & Brewer MKIV & single & 0.60 & $290-330$ \\
Reading, England & S1.5 & GBR & Optronics 742 & double & 1.60 & $280-500$ \\
Lerwick, Scotland & 60.1 & GBL & Bentham DTM300 & double & 0.60 & $280-500$ \\
Thessaloniki, Greece & 40.6 & GRT & Brewer MKIII & double & 0.64 & $285-365$ \\
\hline
\end{tabular}

FWHM is full width at half maximum

by operating at its home site, was using its regular calibration protocol.

Errors arise from many different sources during the calibration and operation of spectroradiometrs, which reduce their accuracy and increase the uncertainty of their measurements, so that a complete error budget for each instrument can hardly be achieved, even after laborious experimentation and analysis. Some types of error are difficult to quantify, but substantial efforts have been made to establish the best possible error estimates for each of the above instruments, either in the laboratory [e.g., Webb et al., 1994] of by comparing their measurements during intercomparison campaigns. These estimates are summarized for each instrument in Table 2.

The most important error for this specific experiment was the angular response of the spectroradiometrs, since most of the measurements were made at low solar elevations. From laboratory measurements it was found that the absolute error of each instrument due to its cosine response lies between $-20 \%$ and $-30 \%$ for incidence angles higher than $60^{\circ}$. However, the resultant systematic error in the measured global solar irradiance is less than half of this. This happens because a large part of global UV radiation is received as diffuse radiation, which, contrary to the direct component, is not affected strongly by the cosine error. Moreover, at low Sun conditions the direct solar irradiance is very weak, accounting only for a small fraction of the global irradiance. In practice, the relative error among all instruments in this campaign is even smaller, of the order of $5 \%$, as their cosine errors are similar. An unavoidable error source in spectroradiometry is the uncertainty of the spectral irradiance standards, which is typically about $2 \%$ to $3 \%$, depending on wavelength. Of similar magnitude is the transfer uncertainty of the lamp calibration to the spectroradiometer. A well-maintained and highquality spectroradiometer is not expected to vary by more than about $2 \%$ between successive spectral irradiance lamp calibrations.

The errors introduced by stray light are negligible for double monochromators but are quite significant for single monochro- mators. However, near-field stray light (due to the slit width) may produce appreciable systematic errors, which become more important at lower wavelengths. Fortunately, in our case most of the instruments had comparable slit widths (except the Reading, England (GBR) instrument), and therefore the contribution of this error is expected to be small when comparing measurements. The GBR instrument will overestimate radiation at the shortest wavelengths, relative to the other spectrometers. Finally, the errors introduced by inaccurate wavelength alignment of the spectrometers depend strongly on wavelength, and therefore in Table 2 the estimated error in the erythema-weighted irradiance is presented for each instrument. For these instruments, the remaining errors, such as dark current, amplifier noise, detector linearity, etc., do not contribute significantly to the overall error budget .

Most of the instruments have been intercompared several times in the past, either in pairs or in large intercomparison campaigns [Bais and Blumthaler, 1995; Gardiner and Kirsch, 1995; Blumthaler et al., 1994b]. The experience from these campaigns showed that transportation of instruments can cause shifts in their absolute calibration. Therefore, to ensure comparability among the measurements at the different locations, it was decided to perform a 2-day intercomparison by moving one of the spectroradiometers to each site prior to the beginning of the intensive campaign. The instrument of the University of Innsbruck (ATI) was used as a traveling standard to check the absolute calibration of the other instruments. At all sites the stability of the calibration of the ATI instrument was continuously controlled by comparison with a broadband UVB detector (Robertson-Berger UV-biometer). For that purpose the UVbiometer was sampled 10 times during the UV part of each spectral scan (within about $2 \mathrm{~min}$ ). Then the measured spectrum was weighted with the spectral sensitivity of the UV-biometer and integrated over that range. The ratio of this integral to the average of the $10 \mathrm{UV}$-biometer readings is nearly constant under all atmospheric conditions, as long as both systems operate satisfactorily. The only factor that may disturb the stability of this ra-

Table 2. Estimated Error Budget of the Spectroradiometers

\begin{tabular}{lccccc}
\hline Error Source & ATI & GRR & GBL & GBR & GRT \\
\hline Uncertainty of calibration lamp & 3 & 4 & 4 & 3 & 3 \\
Transfer of calibration & 3 & 2 & 2 & 2 & 2 \\
Stability of calibration & 2 & 2 & 2 & 2 & 0.5 \\
Wavelength alignment error, & 0.4 & 0.5 & 0.4 & 2 & 0.5 \\
$\quad \begin{array}{l}\text { in erythema weighted irradiance } \\
\text { Stray light error at 305 nm }\end{array}$ & $<0.1$ & 5 & $<0.1$ & 5 & $<0.1$ \\
Cosine error between $0^{\circ}-60^{\circ}$ & $8-16$ & $4-12$ & $5-12$ & $7-15$ & $3-10$ \\
\hline
\end{tabular}

All values are in percent. 

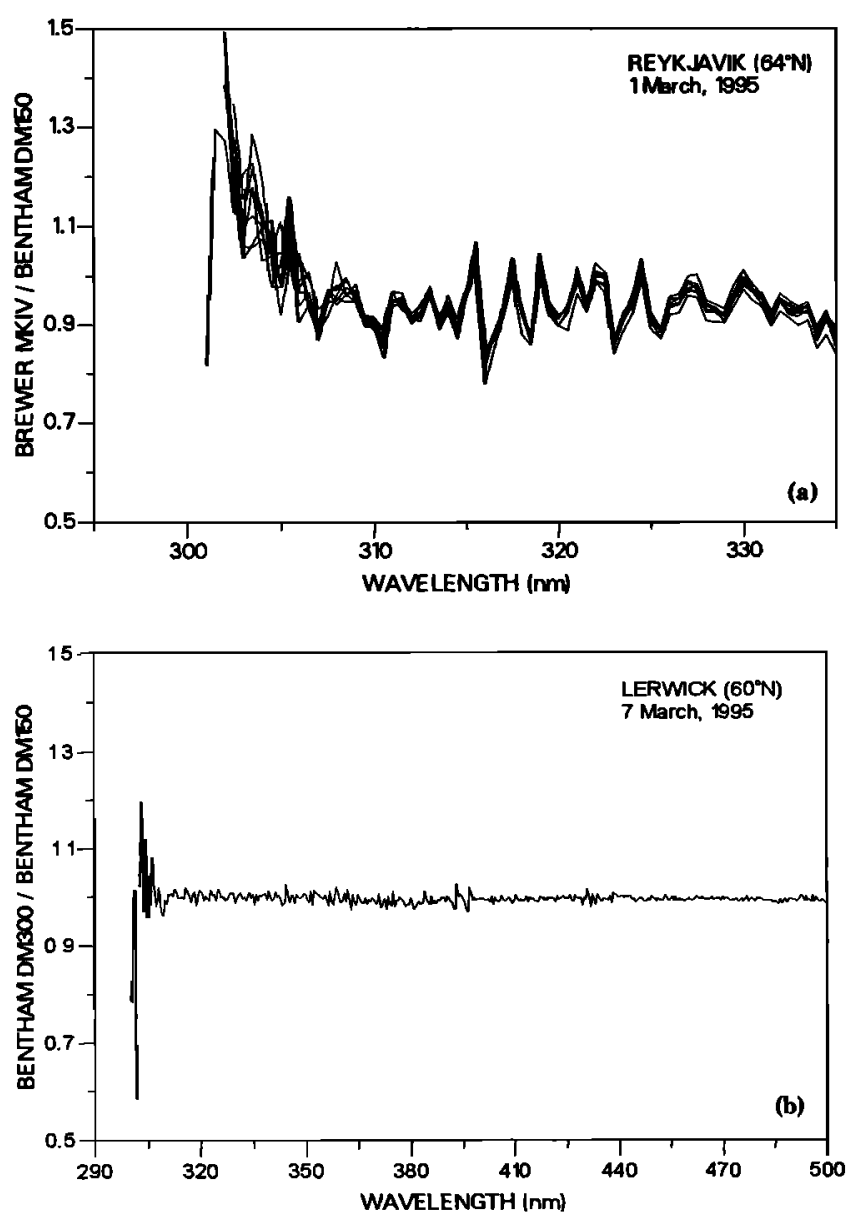

Figure 1. Ratios of selected, synchronized global solar irradiance spectra obtained within 1 day by the (a) ATI and GRR instruments at Reykjavik, Iceland, and (b) ATI and GBL instruments at Lerwick, Scotland.

tio is the slightly different cosine responses of the two systems. This may result in a variation of the ratio of about $\pm 2 \%$, depending on the atmospheric conditions (solar elevation, aerosols, clouds). During the SESAME campaign the ratio was constant within about $\pm 3 \%$, which is in agreement with the results at Innsbruck before and after the transportation of the instrument. This provides additional evidence that the calibration of the ATI instrument was stable during the whole period of measurements. It should be mentioned here that during the intercomparison exercises each instrument used its own calibration, and examples of these comparisons are shown in Figures 1 and 2.

Figure la shows ratios of selected global irradiance spectra obtained simultaneously by the ATI and the Reykjavik, Iceland (GRR) instruments at Reykjavik, during a single day from sunrise to sunset. All spectra were synchronized; that is, each wavelength was sampled simultaneously by both instruments, to eliminate any atmospheric noise induced by changing weather conditions, mainly by fast moving clouds. It appears from Figure la that there is a remarkable repeatability between the two instruments during the whole day. The marked structure of the ratios is a result of the different slit functions of the two instruments [Bais and Blumthaler, 1995; Gardiner and Kirsch, 1995]. At the lower UVB wavelengths $(\lambda<305 \mathrm{~nm})$ the stray light effect of the single-monochromator Brewer is evident, being as much as $30 \%$ at the lowest detectable wavelength (about 302 $\mathrm{nm}$ ), under these low-Sun conditions. However, as shown by Bais et al. [1996], the overall error introduced by stray light in the calculation of the erythemal irradiance by the singlemonochromator Brewer is relatively low, of the order of $1 \%$. Finally, in terms of their absolute calibration, the ATI and GRR instruments show a difference of about $5 \%$ in the spectral range 305-330 nm. More than half of this difference was proved to be a building effect, obstructing differently the two instruments, and consequently, the agreement between the two instruments could really be within $2 \%$.

The second example refers to the comparison of the ATI and the Lerwick, Scotland (GBL), instruments, performed at Lerwick during March 7, 1995. Ratios of synchronized global spectra are shown in Figure lb. As in the previous example, the absolute agreement between the two spectroradiometers is within $2 \%$. Here the agreement is better also at the low wavelengths, since both spectrometers are double monochromators and they have similar slit functions. The results from both comparisons are encouraging, allowing direct comparison of the measurements performed by the three instruments at different sites. The good agreement found in the intercomparisons is clearly within the expected error limits of the instruments, as described in Table 2.

The intensive campaign took place in March 1995, and the locations at which each instrument was operating are shown in Table 1. Spectral measurements of the global solar UV irradiance were performed at half-hour intervals from sunrise to sunset at all locations, except for the ATI instrument, which was operating only in periods without precipitation. At all sites, direct Sun measurements made during cloud-free intervals were used to derive the total ozone content. Total ozone at Esrange and Lerwick was calculated from direct Sun spectra, with the aid

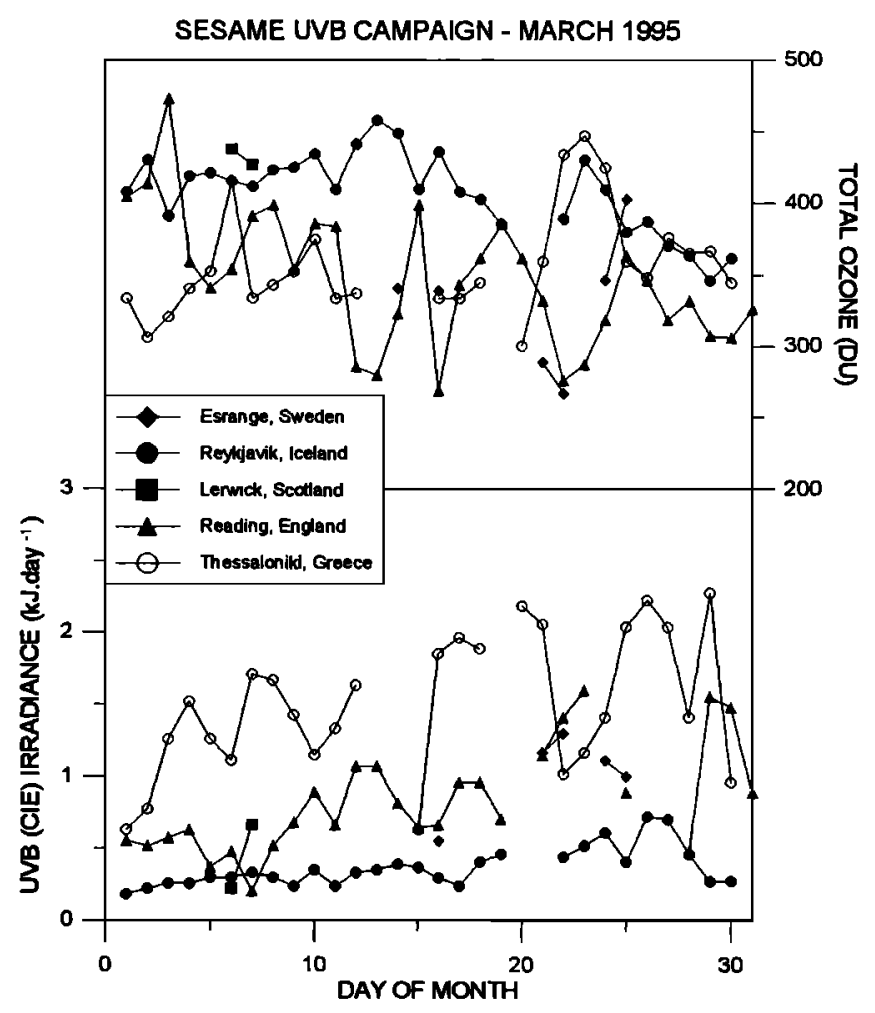

Figure 2. Time series of (top) total ozone and (bottom) daily integral of UV erythemal solar irradiance measured at the five European sites during March 1995. 
of a radiative transfer model [Huber et al., 1995], while in Reykjavik and Thessaloniki, total ozone was obtained by the Brewer spectrophotometers using their well-known standard methodology. Finally, for Reading we used total ozone measurements, as measured at the station of Camborne by a Dobson spectrophotometer.

The calculation of the erythemal irradiance was made by integration of global solar irradiance spectra, convolved with the Commission Internationale de l' Eclairage (CIE) erythemal action spectrum [McKinlay and Diffey, 1987], in the region from 280 to $400 \mathrm{~nm}$. In the case of the Brewer instruments, which have an upper wavelength limit, the integral in the range above the highest measurable wavelength $\lambda_{\max }$ (see Table 1) was calculated as a proportion of the irradiance measured at this wavelength. More specifically, we used measured global spectra by the ATI instrument to calculate the relation between the CIEweighted integral in the region $\lambda_{\max }-400 \mathrm{~nm}$ and the irradiance at $\lambda_{\max }$. By using this relation, we are able to correct the erythemal irradiance derived from the Brewer instruments for the missing (UVA) part in the measured spectra. From comparisons between Brewer-derived erythemal irradiances and simultaneously recorded measurements of a Yankee Environmental Systems Inc. (YES) broadband detector at Thessaloniki, we are convinced that this simulation gives satisfactory results, since it is practically unaffected by total ozone and depends only slightly on solar zenith angle.

Global solar irradiance spectra are available for the period of the campaign at four sites only. Unfortunately, technical problems did not allow the instrument at Lerwick to perform continuous measurements throughout the whole campaign, but it is included in the study since it provides links to the GBR instrument operating at Reading, which uses the same calibration facility and is run regularly side by side by the same operators. Despite this unexpected failure the remaining four instruments provide representative geographical coverage, and therefore most of the objectives of the campaign were satisfied.

\section{Results and Discussion}

After ensuring comparability among the UV spectral measurements performed by the participating instruments, the measurements made at each site can be safely compared. Figure 2 (bottom) shows the time series of the daily integral of the UV erythemal irradiance as measured at the five sites. The major factors governing the variation of the daily irradiances at these sites are the cloud cover, the total ozone amount, and the variation of the solar zenith angle caused by the differences in latitude. The length of the day is not an important factor in this case, because the period of measurements is very close to the spring equinox. For comparison purposes the corresponding time series of total ozone at all sites is presented in Figure 2 (top).

The biggest decreases in ozone occurred in Reading, followed by enhanced levels of the erythemal solar irradiance. Indeed, total ozone at Reykjavik was rather high during the whole month of March. Consequently, the erythemal solar irradiance at Reykjavik was the lowest measured at all sites, as a result of both the high ozone levels and the presence of clouds. Thessaloniki presented the highest levels of the erythemal solar irradiance, as expected by its latitudinal difference from the other northern stations. However, short-period, low UV levels were also recorded, as a result of increased ozone and cloudiness. Ozone in Esrange experienced high variability with extremely low values when the polar vortex was over the site. These low ozone values resulted in almost doubled levels of the erythemal
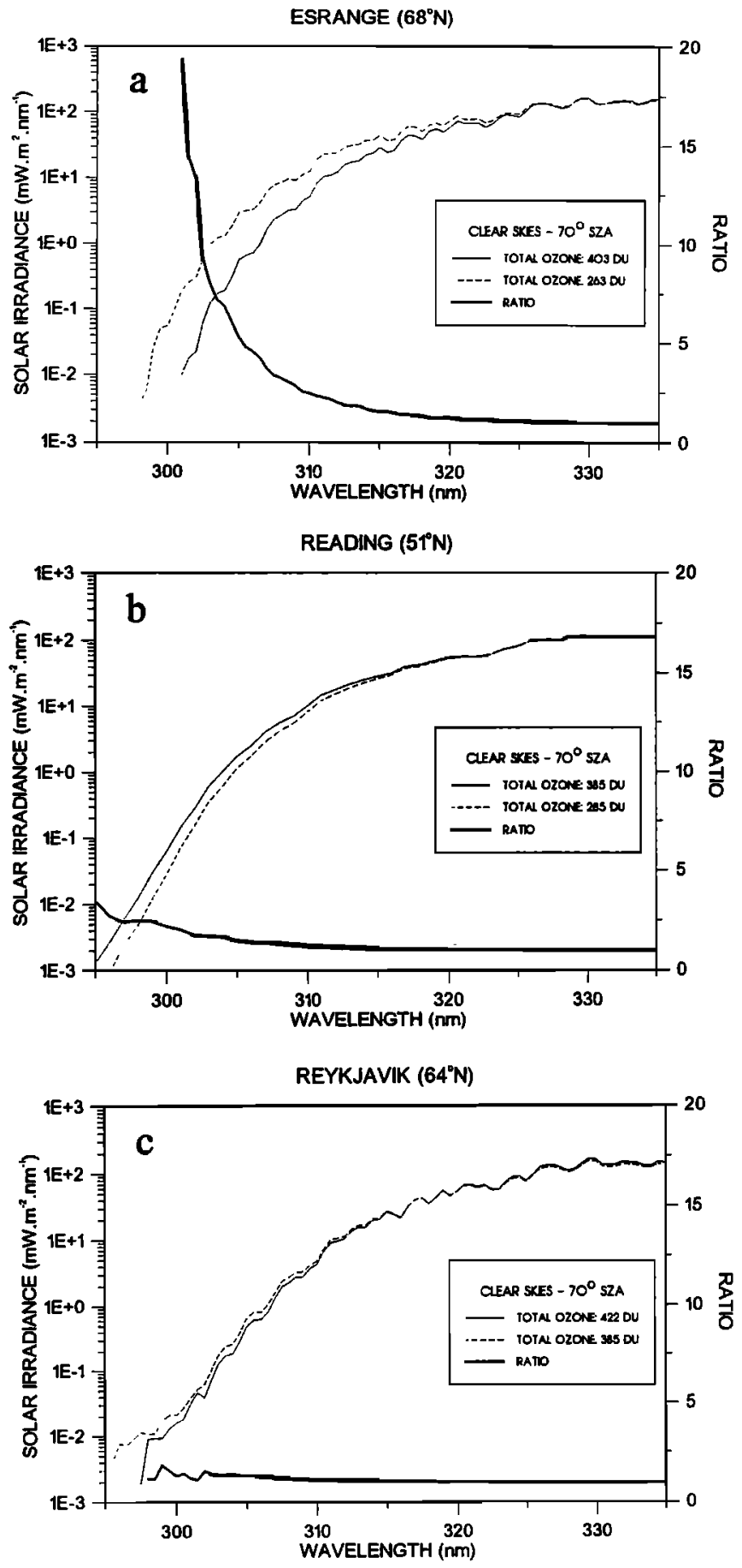

Figure 3. Examples of global solar UV irradiance spectra recorded under clear skies at a solar zenith angle of $70^{\circ}$ and on pairs of days with extreme ozone levels at (a) Esrange, (b) Reading, and (c) Reykjavik. The thick solid curves represent the ratio of each pair of spectra.

solar irradiance reaching the Earth's surface. The measurements presented in Figure 2 show the "real situation" at the selected sites of both the ozone and the solar UV during the period of study.

The existence of such detailed measurements provides an opportunity to investigate the extent to which various factors may control the levels of solar ultraviolet irradiance at the ground. Ozone is one of the most important, but its effect is often masked by the variation of other factors, such as the solar eleva- 
tion and the cloud cover [e.g., Bais et al., 1993]. Use of clear-sky UV spectra at constant solar zenith angles can eliminate the interference of these factors. In Figure 3 we present examples of global spectra recorded under clear skies, at the same solar zenith angle, and on pairs of days with extreme ozone levels at three selected sites. The most striking example is the comparison of UV spectra measured at Esrange (Figure 3a) during two days with ozone levels differing by about 140 Dobson units (DU). The effect on the corresponding irradiances is more evident at the lower UVB wavelengths, where the solar irradiance at $300 \mathrm{~nm}$ has increased almost 20 times, as seen from the ratio of the two spectra plotted as thick curves in Figures 3a-3c. On the contrary, in the example of Reading (Figure $3 b$ ) the ozone difference of about $100 \mathrm{DU}$ resulted only in a 4 times increase of solar UV irradiance at $300 \mathrm{~nm}$. The ratio at these low UV wavelengths may be influenced by the wider slit width of the Optronics spectrometer (see Table 1). Finally, at Reykjavik the largest ozone difference observed was much smaller (about 40 DU) and therefore the expected increase of UV irradiances was significantly smaller. As it appears from Figure 3c, there is large uncertainty in the calculated ratio of the two spectra at the low UV wavelengths. This uncertainty is partly a result of the stray light effect of the single-monochromator spectrometer. Additional causes may be the small difference in total ozone between the 2 days and the low intensity of solar irradiance caused by the relatively high ozone levels and the high solar zenith angles.

As mentioned before, the presence of clouds masks the effect of ozone variations on solar UV irradiances measured at the ground. At northern latitudes, enhanced cloud cover conditions are very common. A well-known method to remove the cloud effect from solar UV spectra is to normalize them by the irradiance at higher wavelengths where ozone absorption is of lesser importance. The wavelength dependency of the cloud effect on solar irradiance is very weak in the UVB and UVA spectral region [Bais et al., 1993; Blumthaler et al., 1994a], so that the UVAintegrated irradiance can be used safely to remove the cloud effect from the recorded erythemal irradiances. It should be mentioned that this method also removes any other factor whose effect on solar UV radiation is independent of wavelength in this relatively narrow spectral region. Figure 4 shows the ratio of the CE-weighted erythemal irradiance $(280-400 \mathrm{~nm})$ to the integral of the UVA irradiance ( $320-400 \mathrm{~nm}$ ), as measured by three different instruments at $70^{\circ}$ solar zenith angle during the period of study. Superimposed in each of Figures $4 a, 4 b$, and $4 c$ is the time series of total ozone on the same days (plotted in reversed scale) to demonstrate the significant anticorrelation between the UVB/UVA ratio and total ozone. It appears from these figures that the ozone-induced variation of the UV erythemal irradiance during March 1995 was large at all three sites, occasionally being even doubled. However, the ozone-induced variability represents only about one third of the total variability of UV erythemal irradiance. This is evident from Table 3, which summarizes a simple statistical analysis related to the variability of these parameters, including the coefficient of variation $\sigma_{r}$ calculated for each parameter and at each site as the ratio of the standard deviation to the mean value of each parameter.

One may notice the similarity in the magnitude of $\sigma_{r}$ for the ratio UVB/UVA and for total ozone. The results of Table 3 also suggest that the effect of clouds or other wavelength independent factors on the variability of UV erythemal irradiance is at least as important as the effect of ozone. In the case of Thessaloniki the effect of clouds becomes even more important, being in this particular case 3 to 4 times larger than that of ozone. Finally, il
ESRANGE (SE)
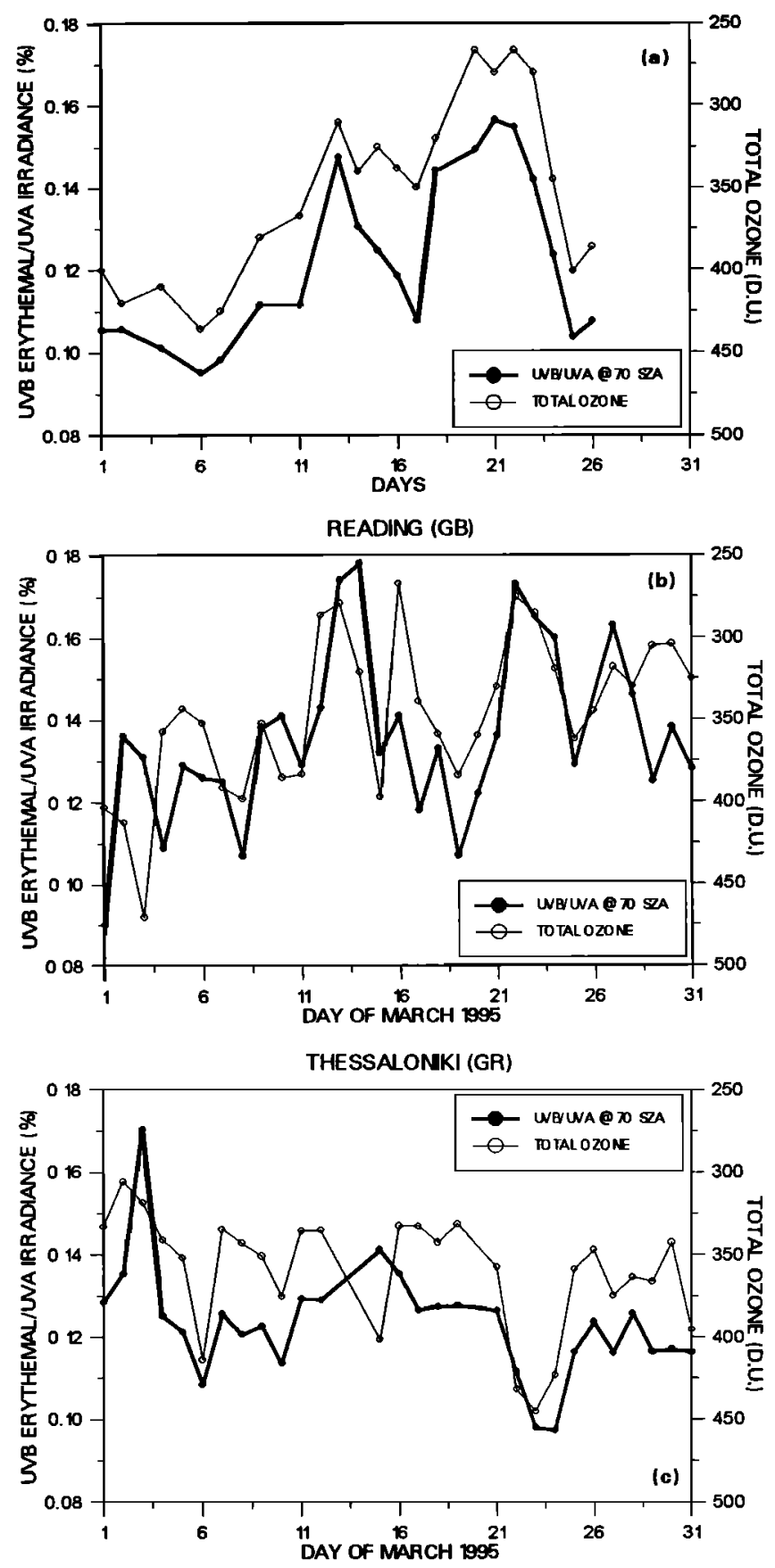

Figure 4. Ratios of the Commission Internationale de $\mathrm{l}^{\prime}$ Eclairage (CIE) weighted erythemal solar irradiance (280-400 $\mathrm{nm}$ ) to the integral of the UVA irradiance $(320-400 \mathrm{~nm})$ measured at a $70^{\circ}$ solar zenith angle at (a) Esrange, (b) Reading, and (c) Thessaloniki during March 1995 (thick curves). The thincurves correspond to the time series of total ozone measured on the same days at each site.

should be noted here that the application of this methodology, i.e., to remove the cloud effects by using the ratio UVB/UVA, depends strongly on the stability of the cloud conditions. Changes in the optical depth of clouds during the measurements may produce significant wavelength dependence in the measured spectra. Examples of such cases can be seen in Figure 4, on the days where the overall anticorrelation becomes worse. 
Table 3. Summary of Statistical Results Related to the Variability of UV Erythema Solar Irradiance at $70^{\circ}$ Solar Zenith Angle, the Ratio UVB/UVA, and the Total Ozone Column During March 1995

\begin{tabular}{|c|c|c|c|c|c|c|c|c|c|c|}
\hline \multirow[b]{2}{*}{ Sites } & \multicolumn{3}{|c|}{$\begin{array}{c}\text { Erythema Irradiance, } \\
\qquad \mathbf{m W ~ m}^{-2}\end{array}$} & \multicolumn{3}{|c|}{$\begin{array}{c}\text { UVB/UVA, } \\
\%\end{array}$} & \multicolumn{3}{|c|}{$\begin{array}{l}\text { Total Ozone, } \\
\text { DU }\end{array}$} & \multirow{2}{*}{$\begin{array}{l}\text { Number of } \\
\text { Observations }\end{array}$} \\
\hline & Mean & $\boldsymbol{\sigma}$ & $\sigma_{r}$ & Mean & $\boldsymbol{\sigma}$ & $\sigma_{r}$ & Mean & $\sigma$ & $\sigma_{r}$ & \\
\hline Thessaloniki & 11.45 & 4.37 & 0.38 & 0.123 & 0.014 & 0.11 & 360.1 & 35.5 & 0.10 & 28 \\
\hline Reading & 12.99 & 3.50 & 0.27 & 0.136 & 0.021 & 0.15 & 346.3 & 46.6 & 0.13 & 30 \\
\hline Reykjavik & 13.73 & 2.46 & 0.18 & 0.118 & 0.008 & 0.07 & 406.2 & 27.4 & 0.07 & 31 \\
\hline Esrange & 12.08 & 3.92 & 0.32 & 0.124 & 0.020 & 0.16 & 345.2 & 54.1 & 0.16 & 23 \\
\hline
\end{tabular}

DU is Dobson Units, $\sigma$ is the standard deviation of the mean, and $\sigma_{r}$ is the coefficient of variation

From Table 3 it is also interesting to compare the mean levels of the erythemal solar irradiance measured at various sites. Apparently, at all sites the mean values for this particular period were of the same order, since all irradiances were measured at the same solar zenith angle $\left(70^{\circ}\right)$. Reykjavik presents the highest values of the erythemal irradiance, despite its higher ozone levels compared with the other stations. It seems that the amount of clouds during this period was much smaller than at the other sites, even compared to the most southerly site of Thessaloniki. It appears also that the variability of all parameters (erythemal irradiance, UVB/UVA, and ozone) at Reykjavik was weak during the period of study, and this can be seen also from the smooth time series of the daily integrals of Figure 2. Finally, the fact that the UVB/UVA ratio remained stable at all sites provides additional evidence that the instruments were operating reliably and producing spectra of good quality at each site.

\section{Conclusions}

From the intensive campaign of UV spectral measurements it is apparent that most of the existing instrumentation can be safely used to perform reliable and consistent measurements, even under unfavorable environmental conditions. This was proved by the intercomparison of the instruments with the traveling spectroradiometer, as well as by the comparability of the UV data collected at all sites.

The ratio of the erythemal solar irradiance to the integral of the UVA solar irradiance is almost free of cloud interference and depends only on total ozone and the solar zenith angle. As it appeared from this particular data set, clouds are responsible for a large fraction of the erythemal irradiance variability, their influence being at least of equal importance to that of ozone. Occasionally, cloud cover variability can explain even two thirds of the variability of erythemal solar irradiance.

The daily integral of erythemal solar irradiance measured at all sites varied between 0.2 and $2.2 \mathrm{~kJ} \mathrm{~m}^{-2}$ during March 1995 . The lowest values were observed at Reykjavik, dominated by the increased total ozone and cloudiness, and the highest values were at Thessaloniki, due to its latitudinal difference from the other sites.

Aclnowledgments. This work was partly supported by the European Commission, through the CAMSSUM project (contract EV5V-CT93-0353).

\section{References}

Bais, A. F., and M. Blumthaler, A small scale intercomparison of UV spectroradiometers, in Proceedings of the first European Symposium on Effects of Environmental UV Radiation, Munich, 27-29 October 1993, Publ. EUR 15607, pp. 77-83, Eur. Comm., Brussels, 1995.

Bais, A. F., C. S. Zerefos, C. Meleti, I. C. Ziomas, and K. Tourpali, Spectral measurements of solar UVB radiation and its relations to total ozone, $\mathrm{SO}_{2}$, and clouds, J. Geophys. Res., 98(D3), 5199-5204, 1993.

Bais, A. F., C. S. Zerefos, C. Meleti, I. C. Ziomas, K. Tourpali, V. Karaouza, and D. S. Balis, Variability of solar UVB radiation at high and middle latitudes during EASOE 91/92, Geophys. Res. Lett., 2l(13), 1403-1406, 1994.

Bais A. F., C. S. Zerefos, and C. T. McElroy, Solar UVB measurements with the double- and single-monochromator Brewer ozone spectrophotometers, Geophys. Res. Lett., 23(8), 833-836, 1996.

Blumthaler, M., W. Ambach, and M. Salzgeber, Effects of cloudiness on global and diffuse UV irradiance in a high-mountain area, Theor. Appl. Climatol., 50, 23-30, 1994a.

Blumthaler, M., A. R. Webb, G. Seckmeyer, A. F. Bais, M. Huber, and B. Mayer, Simultaneous spectroradiometry: A study of solar UV irradiance at two altitudes, Geophys. Res. Lett., 21(25), 2805-2808, 1994 b.

Gardiner, B. G., and P. J. Kirsch, Setting standards for European ultraviolet spectroradiometers, Air Pollut. Res. Rep. 53, 138 pp., Comm. of the Eur. Communities., Luxembourg, 1995.

Henriksen, K., S. Claes, T. Svenoe, and K. Stamnes, Spectral UV and visible measurements in the Barents Sea., J. Atmos. Terr. Phys., 54, 1119-1127, 1992.

Huber, M., M. Blumthaler., and W. Ambach, Total atmospheric ozone determined from spectral measurements of direct solar UVB irradiance, Geophys. Res. Lett., 22(1), 53-56, 1995.

Jokela, K., K. Leszczynski, and R. Visuri, Effects of arctic ozone depletion and snow on UV exposure in Finland, Photochem. Photobiol., S8(4), 559-566, 1993.

McKinlay, A F., and B. L. Diffey, A reference action spectrum for ultraviolet induced erythema in human skin, in Human Exposure to Ultraviolet Radiation: Risks and Regulations, edited by W. F. Passchier, and B. F. M. Bosnjakovic, pp. 83-87, Elsevier, New York, 1987.

Svenoe, T., M. Olsen, K. Henriksen, and K. Stamnes, Measurements of lunar and solar ultraviolet spectra at high latitudes, Geomagn. Aeron., 39, 189-194, 1994.

Webb, A. R., B. G. Gardiner, M. Blumthaler, P. Forster, M. Huber, and P. J. Kirsch, A laboratory investigation of two ultraviolet spectroradiometers, Photochem. Photobiol., 60(1), 84-90, 1994.

A. F. Bais and C. S. Zerefos, Physics Department, Laboratory of Atmospheric Physics, Aristotle University of Thessaloniki, Thessaloniki 54006, Greece. (e-mail: abais@ccf.auth.gr, zerefos@ccf.auth.gr)

M. Blumthaler, Institute of Medical Physics, University of Innsbruck, Mullerstrasse 44, A-6020, Innsbruck, Austria. (e-mail: Mario.Blumthaler@uibk.ac.at)

B. G. Gardiner, P. J. Kirsch and T. J. Martin, British Antarctic Survey, High Cross, Madingley Road, Cambridge, CB3 0ET, England. (e-mail: Brian.Gardiner@bas.ac.uk; Peter.Kirsch@bas.ac.uk; Timothy.Martin@bas.ac.uk)

J. Groebner, Atmospheric Environment Service, Environment Canada, ARQX, 4905 Dufferin st., North York, Ontario, M3H ST4, Canada. (email: Julian.Groebner@ec.gc.ca)

T. Svenoe, Norwegian Institute for Air Research, P.O. Box 1245, N9001, Tromsoe, Norway. (e-mail: Trond.Svenoe@nilu.no)

A. R. Webb, University of Manchester, Institute of Science and Technology, P.O. Box 88, Sacksville street, Manchester, M60 1QD, England. (email: Ann.Webb@nessie.mcc.ac.uk)

(Received September 18, 1995; revised July 24, 1996;

accepted November 4, 1996.) 